\title{
Atrial Septal Defect Device Closure. Is Balloon Sizing Necessary?
}

\author{
Ali Eshraghi ${ }^{1}$, Ehsan Aghaei-Moghadam ${ }^{2,3,4}$, Aliakbar Zeinaloo (iD) ${ }^{2,3,4}$, Elaheh Malakan Rad (iD ${ }^{2,3,4}$, \\ Keyhan Sayadpour Zanjani (iD) ${ }^{2,3,4,{ }^{*}}$ and Seyyedeh Fatemeh Ghalibafan (iD) ${ }^{5}$ \\ ${ }^{1}$ Children's Hospital of Fatemeh Masoumeh, Qom University of Medical Sciences, Qom, Iran \\ ${ }^{2}$ Children's Medical Center (Pediatric Center of Excellence), Tehran University of Medical Sciences, Tehran, Iran \\ ${ }^{3}$ Pediatric Department, Tehran University of Medical Sciences, Tehran, Iran \\ ${ }^{4}$ Pediatric and Adolescent Cardiovascular Research Center, Tehran University of Medical Sciences, Tehran, Iran \\ ${ }^{5}$ Mashhad University of Medical Sciences, Mashhad, Iran \\ "Corresponding author: Pediatric Department, Tehran University of Medical Sciences, Tehran, Iran. Email: ksayadpour@yahoo.com
}

Received 2020 August 01; Revised 2020 October 20; Accepted 2020 November 20.

\begin{abstract}
Objectives: This study compared the success rate of atrial septal defect device closure in children with and without balloon sizing during the procedure.

Methods: This four-year, combined retrospective and prospective study was performed at a single center. All participants underwent transcatheter closure under transthoracic echocardiography and the success rate was analyzed considering the effect of balloon sizing.

Results: Eighty-eight patients with a mean age of $6.48 \pm 3.32$ years were enrolled. Balloon sizing was performedor in 39 ( $44 \%$ ) patients. It didn't change the success rate compared to 49 (56\%) patients without balloon sizing. Likewise, age and sex had no effect on thesuccess rate. However; the failure rate was higher in patients with larger defects.

Conclusions: The study demonstrated that balloon sizing did not influence the success rate of atrial septal defect device closure, and a precise measurement by echocardiography can be as successful as balloon sizing.
\end{abstract}

Keywords: Occlutech Septal Occlude, Transthoracic Echocardiography, Balloon Sizing, Device Size, Erosion, Children

\section{Background}

Atrial septal defect (ASD) is currently one of the most common congenital heart diseases (CHD) with a higher incidence in females $(1,2)$. Right ventricle volume overload, pulmonary hypertension, arrhythmia and paradoxical emboli can be serious sequel of an unrepaired ASD, especially in the older ages (3). The first surgical closure of ASD was performed by Murray et al in 1948. Later on, King and Mills could successfully innovate the transcatheter closure in $1976(4,5)$. Whenever it can be applicable, this method is much preferred due to its excellent results and fewer complications. The success rate of transcatheter closure is affected by accurate sizing of the defect and its rims $(6,7)$. Different types of echocardiography (transthoracic, transoesophageal or intracardiac) as well as balloon sizing (BS) may be used for defect measurement (8). BS measures the size of ASD in a stretched round form, created by a near zero pressure balloon. However, it has been criticized as it increases the costs, procedure time, and complication rates (9). Echocardiography can show the unstretched defect size as well as its anatomy. The mostly used method is transoesophageal echocardiography (TEE). Meanwhile, intracardiac echocardiography can provide excellent views and also can be used successfully even without BS for the closure of ASD (10). In some reports, inexpensive transthoracic echocardiography (TTE) has been accredited for defect assessment (11).

\section{Objectives}

To offer new insight, this study has been conducted to compare the success rate of ASD device closure between patients for whom defect size was measured by TTE only, and those for whom BS was also performed.

\section{Methods}

This hospital-based, combined retrospective and prospective study was performed from March 2014 to March 2018, at a single center. 


\subsection{Inclusion Criteria}

All children aged $\geq 2$ years old who had secondary ASD with at least a shunt ratio of 1.5/1 were enrolled.

\subsection{Exclusion Criteria}

Patients with multiple defects, sinus venous or primary defect, pulmonary hypertension, and inadequate rim of inferior or superior vena cava were excluded.

\subsection{Data Collection Process}

As study group, we included all patients meeting our criteria. Since BS became out of date, we replaced our TEE machine. Ascontrol group, we selected an approximate number of our latest patients treated with BS under TTE, to minimize any effect of learning bias. The closure method and techniques were similar as previously reported (12). We measured defect size and its rims on substernal view by putting the probe at 12,1:30, 3, and 4:30 o'clock positions (Figure 1). If the view of 1:30 o'clock was suboptimal, we substituted 1:00 o'clock view. The largest measurement among the four values was considered as the largest ASD diameter. As we previously showed, BS yielded in average a $20 \%$ increase to the largest defect diameter (12), and considering some overestimation by BS, we have chosen the device size by adding $15 \%$ to the largest measured size. This value was the final device size or the nearest upscaled number available. We used the stopped-flow technique for BS.

\subsection{Statistical Analysis}

We used SPSS software, version 22 (SPSS Institute, Inc, Chicago, IL, USA). All experimental values are presented as means \pm standard deviation or frequency. Independent $\mathrm{t}$ test was used for comparisons between groups. Undesired effects were analyzed by the chi-square crosstab. P-value less than 0.05 was considered statistically significant. We also performed a subgroup analysis based on age, weight, gender, and defect size.

\section{Results}

Eighty-eight children with a mean age of $6.48 \pm 3.32$ (range 2 to 15 ) years were enrolled in this study. The majority were females ( 53 versus 35 patients). Their weight ranged from 7 to $57 \mathrm{~kg}$ (mean: $21 \pm 9.63$ ). The Occlutech Septal Occluder (Occlutech GmbH, Sweden) was the most common device used ( 82 patients) followed by Nit-Occlud ASD-R (pfm AG, Germany; 3 patients), Cera ASD Occluder (Lifetech Scientific, China; 1 patient), Memoprat ASD Occluder (Lepu Medical, China; 1 patient) and Amplatzer Septal Occluder (Abbott Laboratories, USA; 1 patient).
The size of ASD was measured by both BS and TTE in $39(44 \%)$ patients while in 49 (56\%) patients only TTE was performed. The ASD device closure was failed in 6 patients (6.8\%, 3 patients in each group) due to device prolapse into the right atrium. They were referred for surgical ASD closure. The mean size of the defect was $12.3 \pm 4.81$ millimeter in BS group and $13.4 \pm 3.63$ millimeter in the only TTE group and the difference was not significant (P-value 0.221). The mean size of the device was $17.3 \pm 6.22$ millimeter in BS group and $15.2 \pm 4.5$ millimeter in the only echocardiography group and again, the difference was not significant (P-value 0.343).

BS didn't change the success rate of ASD closure (93\% with BS versus 94\% without it, (P-value 0.573)(Figure 2). The mean size of the defect was 20.33 millimeter in patients with failed procedure compared to 15.72 millimeter with successful procedure, and it was statistically significant (Pvalue $=0.012$ ). We revealed that there was not any significant difference between the success rate of ASD device closure and the age ( $\leq 6$ versus 6 years old), weight ( $\leq 20$ versus $20 \mathrm{~kg}$ ) and gender of the patients (Table 1).

\section{Discussion}

The ASD device closure with inaccurate sizing can result in undesirable complications, including embolization and erosion (13). Although undersizing is associated with residual leaks and embolization, oversizing can bring about arrhythmia, device distortion and aortic root erosion $(13,14)$. Over the past decades, the ASD device closure with BS had been popular; however, it often overestimated the size through overstretching the defect (15). Generally, a device identical or 1-2 millimeter larger than the stretched balloon diameter was implanted (16). On top of defect oversizing, BS often led to septal tearing, additional costs, prolonging fluoroscopy time and inevitable excess irradiation exposure. Hence, it has been gradually omitted from the routine ASD device closure (17-19). The current study indicated that the success rate of ASD device closure didn't change by BS.

Recently, majority of pediatric cardiac interventionists prefer transcatheter ASD device closure without BS techniques. Gupta et al compared the success rate between BS and TEE (device size = largest diameter from 4 measurements, or average if the difference was more than 6 millimeter) and concluded that the success rate was higher in group without BS (90\% vs 67\%) (20). Arora et al. (21) reported their result of ASD closure only by TTE sizing and guiding (device size $=$ largest defect size or up to $2 \mathrm{~mm}$ larger). In 3.6\% of their patients, the device was embolized within 12 hours after the procedure. Vijarnsorn et al. (17) showed that BS was associated with neither oversizing nor 


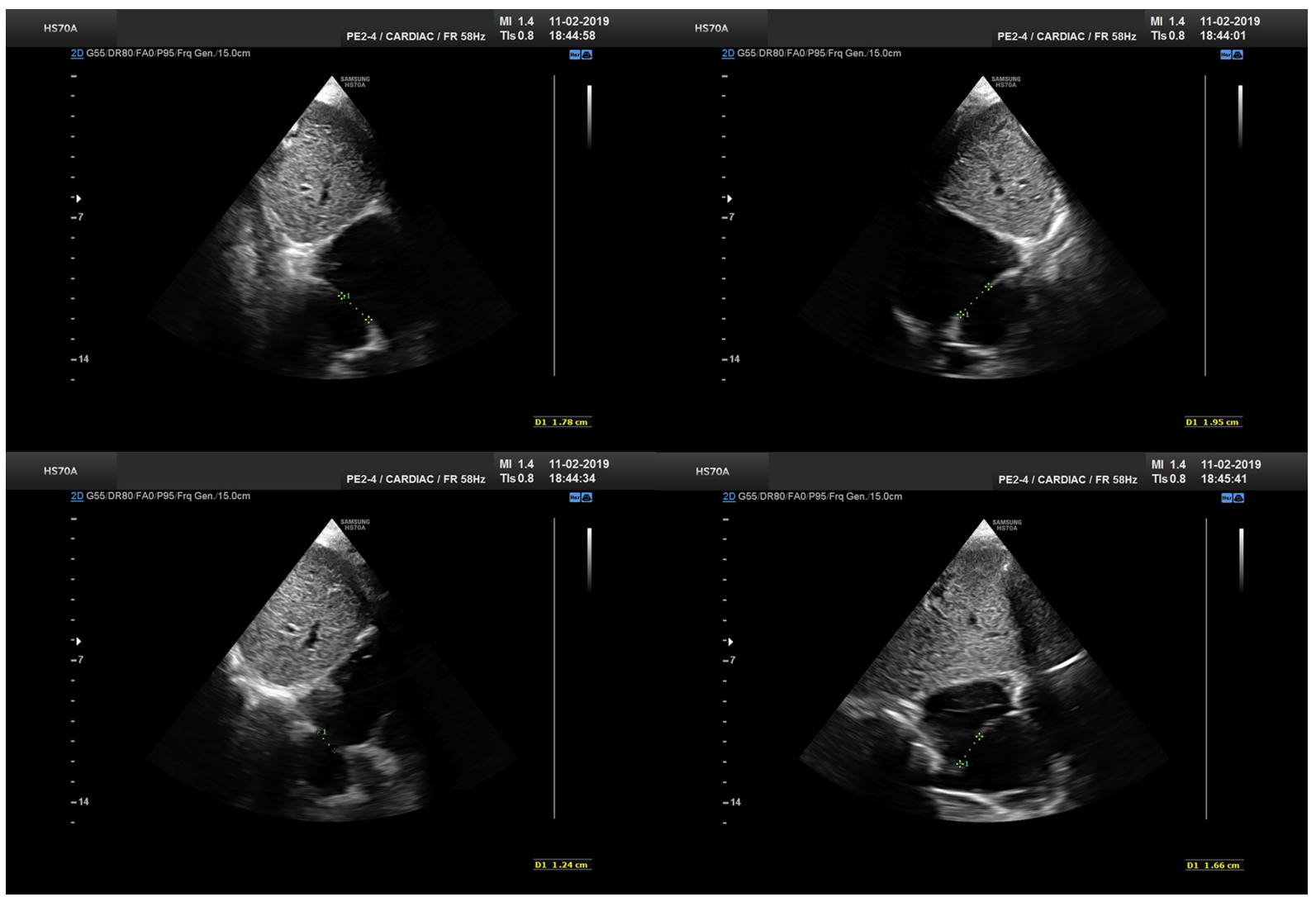

Figure 1. Defect sizing at different angles at substernal views. A, 12 o'clock; B, 13:30; C, 15; D, 16:30.

\begin{tabular}{|c|c|c|c|c|}
\hline Variable & Patients with Successful Closure (\%) & Patients with Failed Closure (\%) & Total Patients (N) & P-Value \\
\hline Gender & & & & 0.890 \\
\hline Female & $49(92.5)$ & $4(7.5)$ & 53 & \\
\hline Male & $33(94)$ & $2(6)$ & 35 & \\
\hline \multicolumn{5}{|l|}{ Age, $y$} \\
\hline$\leq 6$ & $43(95.5)$ & $2(4.5)$ & 45 & 0.868 \\
\hline$>6$ & $39(91)$ & $4(9)$ & 43 & \\
\hline \multicolumn{5}{|l|}{ Weight, kg } \\
\hline$\leq 20$ & $45(96)$ & $2(4)$ & 47 & 0.234 \\
\hline$>20$ & $37(90)$ & $4(10)$ & 41 & \\
\hline
\end{tabular}

better success. Patients who underwent BS had lower device/defect ratio (1.22 vs 1.31, respectively). Bartakian et al. (22) compared BSS (stopped-flow technique) to TTE measurement (device size $=1.2 \times$ average of three views) and reported similar success rate. Zanchetta et al. assessed the defect size using intracardiac echocardiography and could firstly define the specific formula for size of the defect as $\mathrm{r}=\sqrt{ }(\mathrm{C} 2+\mathrm{P} 2)$ in which $\mathrm{r}, \mathrm{C}$ and $\mathrm{P}$ represented for device size, foci half-distance of the fossa ovalis and semi-latus rectum, respectively. They could also determine the equation of $d=\sqrt{ }(a \times b)$ in another study in which $d$, $a$ and $b$ represented the diameter of the device, major axes of intracardiac echocardiography on aortic and four-chamber plane, respectively $(23,24)$. 


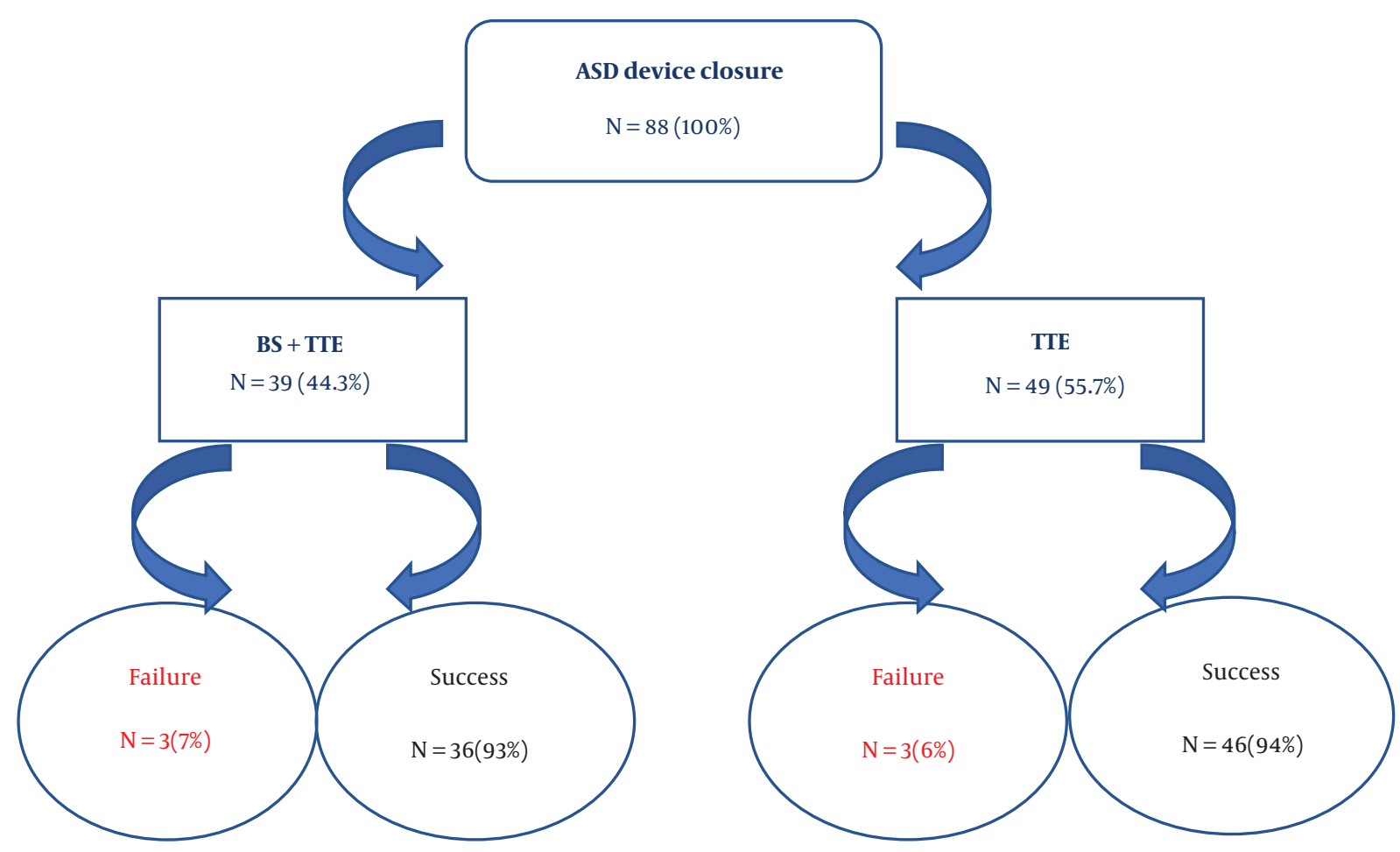

*ASD: atrial septal defect, BS: balloon sizing, TTE: transthoracic echocardiography

Figure 2. The comparison of success rate of ASD device closure considering BS

Totally, most reports used either the largest or average diameter in different views, with acceptable results in both approaches. An addition of $15 \%$ - 20\% to the measured defect size by echocardiography was preferred by most, and yielded better results.

Two-dimensional, transoesophageal, intracardiac, and three-dimensional echocardiography has been used and recommended for ASD sizing $(19,20,25)$. Pan et al. (26) indicated that ASD device closure can be performed under two-dimensional echocardiography, without TTE or fluoroscopy. They also demonstrated that TEE is useful for those with poor echo window.

Erdem et al. (27) emphasized high safety and efficacy of TTE in ASD device closure. They studied 206 patients under TTE compared to the 131 patients with TEE. They concluded that TTE as a faster method provides clear acoustic views and more patient's comfort (27).

The study by Baruteau et al. (28) compared ASD closure with BS measurement under TTE guiding to TEE. Although those under TTE had larger defects and more deficient rims, the success rate under TTE was higher.
Our studies denied any relationship between patients' weight, age and gender with the successful procedure. However, the rate of failure was noticeably higher in the larger defect. Rastogi et al. (29) reported that patient's weight, defect diameter, device size, aortic rim and device/defect ratio played effective role in increasing the success rate of ASD device closure.

\subsection{Limitations}

The study was mostly retrospective. The number of patients whose defects were closed without BS under TTE was limited. Despite these limitations, we found acceptable results.

\subsection{Conclusions}

This study demonstrates that device size selection based on only TTE measurements can provide acceptable results, and adding BS is not necessary for simple ASD closure. 


\section{Acknowledgments}

The authors thank all the staff of Children's Medical Center at Tehran University of Medical Sciences for their kind assistance with this study.

\section{Footnotes}

Authors' Contribution: Keyhan Sayadpour Zanjani designed the experiments and proofread the manuscript. Ali Eshraghi analyzed the data. Fatemeh Ghalibafan wrote the manuscript. Elaheh Malakan Rad and Aliakbar Zeinaloo reviewed TTE scans and revised the manuscript.

Conflict of Interests: The authors declare no conflicts of interest. The authors alone are responsible for the content of this manuscript.

Ethical Approval: This study was approved by Institutional Board Review. All procedures performed in studies involving human participants were in accordance with the ethical standards of the Institutional and National Research Committee and with the 1964 Helsinki Declaration and its later amendments or comparable ethical standards.

Funding/Support: This research received no specific grant from any funding agency, commercial or not-forprofit sectors.

\section{References}

1. Le Gloan L, Legendre A, Iserin L, Ladouceur M. Pathophysiology and natural history of atrial septal defect. $J$ Thorac Dis. 2018;10(Suppl 24):S2854-63. doi: 10.21037/jtd.2018.02.80. [PubMed: 30305945]. [PubMed Central: PMC6174151].

2. Gabriels C, De Meester P, Pasquet A, De Backer J, Paelinck BP, Morissens $\mathrm{M}$, et al. A different view on predictors of pulmonary hypertension in secundum atrial septal defect. Int J Cardiol. 2014;176(3):833-40. doi: 10.1016/j.ijcard.2014.08.009. [PubMed: 25149406].

3. Bloomingdale R, Ashraf S, Cardozo S. Atrial septal defect repair gone wrong. Echocardiography. 2017;34(2):315-6. doi:10.1111/echo.13414. [PubMed: 27928836].

4. Murray G. Closure of Defects in Cardiac Septa. Ann Surg. 1948;128(4):843-52. [PubMed: 17859236]. [PubMed Central: PMC1514107].

5. King TD, Thompson SL, Steiner C, Mills NL. Secundum atrial septal defect. Nonoperative closure during cardiac catheterization. JAMA. 1976;235(23):2506-9. [PubMed: 946659].

6. Hascoet S, Warin-Fresse K, Baruteau AE, Hadeed K, Karsenty C, Petit J, et al. Cardiac imaging of congenital heart diseases during interventional procedures continues to evolve: Pros and cons of the main techniques. Arch Cardiovasc Dis. 2016;109(2):128-42. doi: 10.1016/j.acvd.2015.11.011. [PubMed: 26858142].

7. Liava'a M, Kalfa D. Surgical closure of atrial septal defects. J Thorac Dis. 2018;10(Suppl 24):S2931-9. doi: 10.21037/jtd.2018.07.116. [PubMed: 30305953]. [PubMed Central: PMC6174143].

8. Rigatelli G, Cardaioli P, Hijazi ZM. Contemporary clinical management of atrial septal defects in the adult. Expert Rev Cardiovasc Ther. 2007;5(6):1135-46. doi: 10.1586/14779072.5.6.1135. [PubMed: 18035929].
9. Jang JY, Heo R, Cho MS, Bae J, Hong JA, Lee S, et al. Efficacy of 3D transoesophageal echocardiography for transcatheter device closure of atrial septal defect without balloon sizing. Eur Heart JCardiovasc Imaging. 2018;19(6):684-9. doi: 10.1093/ehjci/jex153. [PubMed: 28633478].

10. Rigatelli G, Nghia NT, Zuin M, Conte L, D'Elia K, Nanjundappa A. Very long-term outcomes of transcatheter secundum atrial septal defect closure using intracardiac echocardiography without balloon sizing. Clin Radiol. 2019;74(9):732 e17-22. doi: 10.1016/j.crad.2019.05.017. [PubMed: 31230756].

11. Moore J, Hegde S, El-Said H, Beekman R3, Benson L, Bergersen L, et al. Transcatheter device closure of atrial septal defects: a safety review. JACC Cardiovasc Interv. 2013;6(5):433-42. doi:10.1016/j.jcin.2013.02.005. [PubMed: 23702008].

12. Zanjani KS, Zeinaloo A, Malekan-Rad E, Kiani A, Bagheri MM. Transcatheter Atrial Septal Defect Closure under Transthorasic Echocardiography in Children. Iran J Pediatr. 2011;21(4):473-8. [PubMed: 23056834]. [PubMed Central: PMC3446133].

13. McElhinney DB, Quartermain MD, Kenny D, Alboliras E, Amin Z. Relative Risk Factors for Cardiac Erosion Following Transcatheter Closure of Atrial Septal Defects: A Case-Control Study. Circulation. 2016;133(18):1738-46. doi: 10.1161/CIRCULATIONAHA.115.019987. [PubMed: 27002094].

14. Ostermayer SH, Srivastava S, Doucette JT, Ko HH, Geiger M, Parness IA, et al. Malattached septum primum and deficient septal rim predict unsuccessful transcatheter closure of atrial communications. Catheter Cardiovasc Interv. 2015;86(7):1195-203. doi: 10.1002/ccd.26102. [PubMed: 26332722].

15. Carlson KM, Justino H, O’Brien RE, Dimas VV, Leonard GJ, Pignatelli $\mathrm{RH}$, et al. Transcatheter atrial septal defect closure: modified balloon sizing technique to avoid overstretching the defect and oversizing the Amplatzer septal occluder. Catheter Cardiovasc Interv. 2005;66(3):390-6. doi: 10.1002/ccd.20443. [PubMed: 16142805].

16. Harper RW, Mottram PM, McGaw DJ. Closure of secundum atrial septal defects with the Amplatzer septal occluder device: techniques and problems. Catheter Cardiovasc Interv. 2002;57(4):508-24. doi: 10.1002/ccd.10353. [PubMed: 12455087].

17. Vijarnsorn C, Durongpisitkul K, Chanthong P, Chungsomprasong P, Soongswang J, Loahaprasitiporn D, et al. Transcatheter closure of atrial septal defects in children, middle-aged adults, and older adults: failure rates, early complications; and balloon sizing effects. Cardiol Res Pract. 2012;2012:584236. doi: 10.1155/2012/584236. [PubMed: 22779023]. [PubMed Central: PMC3388325].

18. Bhaya M, Mutluer FO, Mahan E, Mahan L, Hsiung MC, Yin WH, et al. Live/Real time three-dimensional transesophageal echocardiography in percutaneous closure of atrial septal defects. Echocardiography. 2013;30(3):345-53. doi: 10.1111/echo.12106. [PubMed: 23336391].

19. Hascoet S, Hadeed K, Marchal P, Dulac Y, Alacoque X, Heitz F, et al. The relation between atrial septal defect shape, diameter, and area using three-dimensional transoesophageal echocardiography and balloon sizing during percutaneous closure in children. Eur Heart J Cardiovasc Imaging. 2015;16(7):747-55. doi: 10.1093/ehjci/jeu316. [PubMed: 25617028].

20. Gupta SK, Sivasankaran S, Bijulal S, Tharakan JM, Harikrishnan S, Ajit K. Trans-catheter closure of atrial septal defect: Balloon sizing or no Balloon sizing - single centre experience. Ann Pediatr Cardiol. 2011;4(1):28-33. doi: 10.4103/0974-2069.79619. [PubMed: 21677801]. [PubMed Central: PMC3104527].

21. Arora HS, Bharadwaj P, Chadha DS, Malani S, Ghosh AK, Pathak K, et al. Mid-term Safety and Efficacy of Transcatheter Closure of Ostium Secundum Atrial Septal Defect under Transthoracic Echocardiographic Guidance in Children Weighing Less than $15 \mathrm{Kg}$. Cardiol Angiol. 2019:111. doi: 10.9734/ca/2019/v8i330105.

22. Bartakian S, El-Said HG, Printz B, Moore JW. Prospective randomized trial of transthoracic echocardiography versus transesophageal echocardiography for assessment and guidance of transcatheter closure of atrial septal defects in children using the Amplatzer 
septal occluder. JACC Cardiovasc Interv. 2013;6(9):974-80. doi: 10.1016/j.jcin.2013.05.007. [PubMed: 24050864].

23. Zanchetta M. On-line intracardiac echocardiography alone for Amplatzer Septal Occluder selection and device deployment in adult patients with atrial septal defect. Int J Cardiol. 2004;95(1):61-8. doi: 10.1016/j.ijcard.2003.04.022. [PubMed: 15159040].

24. Zanchetta M, Onorato E, Rigatelli G, Pedon L,Zennaro M, Carrozza A, et al. Intracardiac echocardiography-guided transcatheter closure of secundum atrial septal defect: a new efficient device selection method. J Am Coll Cardiol. 2003;42(9):1677-82. doi: 10.1016/j.jacc.2003.08.023. [PubMed: 14607459].

25. Johri AM, Witzke C, Solis J, Palacios IF, Inglessis I, Picard MH, et al. Real-time three-dimensional transesophageal echocardiography in patients with secundum atrial septal defects: outcomes following transcatheter closure. J Am Soc Echocardiogr. 2011;24(4):431-7. doi: 10.1016/j.echo.2010.12.011. [PubMed: 21262563].

26. Pan XB, Ou-Yang WB, Pang KJ, Zhang FW, Wang SZ, Liu Y, et al. Percuta- neous Closure of Atrial Septal Defects Under Transthoracic Echocardiography Guidance Without Fluoroscopy or Intubation in Children.J Interv Cardiol. 2015;28(4):390-5. doi: 10.1111/joic.12214. [PubMed: 26077469].

27. Erdem A, Saritas T, Zeybek C, Yucel IK, Erol N, Demir H, et al. Transthoracic echocardiographic guidance during transcatheter closure of atrial septal defects in children and adults. Int J Cardiovasc Imaging. 2013;29(1):53-61. doi: 10.1007/s10554-011-9933-z. [PubMed: 21833775].

28. Baruteau AE, Hascoet S, Fraisse A. Transthoracic echocardiography is a safe alternative for assessment and guidance of transcatheter closure of secundum atrial septal defect in children. J Thorac Dis. 2017;9(5):1247-56. doi: 10.21037/jtd.2017.04.47. [PubMed: 28616275]. [PubMed Central: PMC5465139].

29. Rastogi N, Smeeton NC, Qureshi SA. Factors related to successful transcatheter closure of atrial septal defects using the Amplatzer septal occluder. Pediatr Cardiol.2009;30(7):888-92. doi:10.1007/s00246-0099452-z. [PubMed: 19484172]. 